\title{
A qualitative study on factors associated with intimate partner violence in Colombia
}

\author{
Um estudo qualitativo sobre fatores associados à violência \\ por parceiro íntimo na Colômbia
}

Shirley Evelyn Lennon (https://orcid.org/0000-0002-1797-1001) ${ }^{1}$

Adriana María Ramírez Aramburo (https://orcid.org/0000-0001-9022-4814) ${ }^{2}$

Eliana Maritza Morales Garzón (https://orcid.org/0000-0001-9105-372X) ${ }^{2}$

María Adelaida Arboleda (https://orcid.org/0000-0002-1499-8356) 1,2

Andrés Fandiño-Losada (https://orcid.org/0000-0002-3385-7380) ${ }^{1}$

Sara Gabriela Pacichana-Quinayaz (https://orcid.org/0000-0003-1414-151X) ${ }^{1}$

Gloria Inés Rodas Muñoz (https://orcid.org/0000-0003-2423-4381) ${ }^{3}$

María Isabel Gutiérrez-Martínez (https://orcid.org/0000-0002-4198-4638) ${ }^{1}$
${ }^{1}$ Cisalva Institute, Universidad del Valle. Calle 4B No. 36-00 Edificio 135, Barrio San Fernando Viejo. Cali. 760043 Cali Colombia.carlos.fandino@ correounivalle.edu.co ${ }^{2}$ Red de Salud de Ladera ESE. Cali Colombia.

${ }^{3}$ Health, Welfare and Society Group, Unidad Central del Valle del Cauca. Tuluá Colombia.
Abstract Intimate partner violence (IPV) is a human rights violation and a serious global public health problem. This study investigated factors associated with IPV in female survivors in Colombia. Four focus group discussions with female survivors of IPV and 15 key informant interviews with professionals from psychological, social and legal services and community leaders were conducted in Cali and Tuluá. Participant recruitment was via purposive sampling. Transcripts were analysed manually taking a social constructivist standpoint and a content analysis approach. Factors associated with IPV were divided into four themes: cultural beliefs, jealousy, alcohol abuse, and personal history of IPV. The first theme was divided into: patriarchy, gender roles, normalisation of violence, and unawareness of rights, economic dependence, and 'men own women'. The sub-themes were all inter-related and underpinned by patriarchal values. IPV was described as a sociocultural construction formed by patriarchal values ingrained in community and societal norms and individual processes. Therefore, academia, governmental and non-governmental bodies and society are urged to together, create preventative, context specific strategies for individuals, communities and societies.

Key words Intimate Partner Violence, Women's Health, Physical Abuse, Violence
Resumo A violência por parceiro íntimo (VPI) é uma violação dos direitos humanos e um grave problema de saúde pública global. Este estudo investigou fatores associados à VPI em mulheres sobreviventes na Colômbia. Quatro discussões de grupos focais com mulheres sobreviventes de VPI e 15 entrevistas com informantes-chave com profissionais de serviços sócio-médico-legais foram realizadas usando amostragem intencional nas cidades de Cali e Tuluá. As transcrições foram analisadas manualmente, sob um ponto de vista construtivista social e uma abordagem de análise de conteúdo. Os fatores associados à VPI foram divididos em 4 temas: crenças culturais, ciúmes, abuso de álcool e história pessoal da VPI. O primeiro tema foi dividido em: patriarcado, papéis de gênero, normalização da violência, desconhecimento de direitos, dependência econômica e homens possuem mulheres'. VPI foi descrita como uma construção sociocultural formada por valores patriarcais $e$ processos individuais. A VPI é causada por uma complexa interação de diferentes fatores nos níveis do indivíduo, relacionamentos, comunidade e social. Os órgãos governamentais e não governamentais e a sociedade são instados a criar juntos estratégias preventivas e específicas no contexto.

Palavras-chave Violência por parceiro intimo, Saúde da Mulher, Abuso Físico, Violência 


\section{Introduction}

Violence against women is a human rights violation and a global public health problem ${ }^{1}$. Worldwide, the violence most commonly experienced by women is intimate partner violence (IPV), which is the focus of this study. IPV is defined as "[...] physical violence, sexual violence, stalking and psychological aggression (including coercive tactics) by a current or former intimate partner (i.e. spouse, boyfriend/girlfriend, dating partner, or ongoing sexual partner)"2.

Worldwide, $30 \%$ of women are estimated to have experienced physical or sexual violence by a current or previous partner ${ }^{1}$. This statistic is markedly higher in Colombia, where according to survey data, $76 \%$ of women aged 13-49 have experienced IPV ${ }^{3}$. In Colombia, of the 404 cases of female homicides registered in 2018,78 were catalogued as femicides. Additionally, 42,753 cases of IPV against women were recorded ${ }^{4}$. IPV is often underreported, so true figures are likely higher ${ }^{5}$.

Violence against women is both explicit and implicit, where the latter is harder to recognise and measure due to its subtle cultural practices ${ }^{6}$. Cultural factors play a large role in the aetiology of IPV. Gender based violence (GBV) is invisible due to "cultural mechanisms" that "legitimise forms of relationships, discrimination and subjective exercises of control $[. .$.$] These mecha-$ nisms $[\ldots]$ determine how power is exerted and which gender roles are subordinated" (authors' translation $)^{7}$. These practices are innately socialised by health and social institutions where male domination of females is legitimised by their socially constructed role of subjugation.

The ecological framework is commonly used in public health to describe the aetiology of IPV and shows the complex interplay of the different personal, situational and sociocultural factors ${ }^{8}$. This framework consists of four levels: the individual, relationships, community and social, which are all interlinked ${ }^{9}$. The individual level includes one's personal history, such as a history of child abuse $\mathrm{e}^{10}$, witnessing parental abuse $\mathrm{e}^{11}$ and alcohol intake ${ }^{10}$. The relationships level includes factors within family relationships or other close relationships, such as being married ${ }^{12,13}$. At the community and social levels, important factors are gender norms ${ }^{10,11,14}$, poverty, acceptation of violence against women ${ }^{14}$, and weak legislation on $\mathrm{GBV}^{9,15,16}$.

Despite this well-known framework, most studies to date have look at risk and protective factors for IPV at the individual and relationship levels of female and male characteristics, rather than contextual factors, including culture, which is what this study investigates ${ }^{1,8,9,12}$. Colombia has a particularly unique history, where even before the more well-known armed conflict, it has had centuries of violence following the Spanish conquest and colonisation, and the liberation of Colombia as an independent country in 1824. This was followed by violent power and territorial disputes between the liberal and conservative political parties with the indigenous population and other ethnic groups in the middle. The phenomenon of displacement in Colombia began before the recent and more well-known conflict, where waves of migratory groups have moved from the countryside to cities. This in turn saw the displacement of large migratory groups ${ }^{17}$. More recently, Colombia ended over 50 years of armed conflict in 2016. Over 220,000 deaths were caused by the conflict, most of whom were civilians and nearly eight million Colombians were internally displaced ${ }^{18}$. Women were particularly affected by the conflicts and subject to sexual violence, displacement, homicides, kidnapping and forced disappearance ${ }^{19}$. Since the peace process agreement was signed, other pre-existing or new illegal armed groups have still been fighting over land and narcotic businesses, and subsequently the violence and displacement continues ${ }^{18}$.

Colombia has the ninth highest homicide rate in the Americas with 29 homicides per 100,000 population $^{20}$. However, homicides have decreased dramatically in the last two decades ${ }^{21}$. At the community level, male-to-male violence was found to be linked with IPV, rather than violent crime in general ${ }^{22}$. One marker of male-tomale violence is homicides, where in Colombia most of the perpetrators and victims are males. Our study was conducted in Cali, with a homicide rate of 49 per 100,000 population, in one of the districts with the highest number of homicides, Comuna 20, with a rate of around 77 per $100,000^{23}$, and another violent smaller city, Tuluá with a homicide rate of 47 per $100,000^{23}$.

Risk factors for IPV recognised by studies in high-income countries, such as education attainment, may be less relevant compared to low-income countries ${ }^{12}$, or in this study's case, poor populations in middle-income countries. Other factors, which are different in Colombia, compared to most high-income countries, are it's huge displaced population, unique ethnic mix, relatively young population with a median age of 31 , lower socioeconomic status ${ }^{24}$, higher homicide and IPV rates and its illegal drug industry ${ }^{20}$. 
The majority of previous Colombian studies that exist have used survey data; and found that risk factors for IPV include: belonging to a lower socioeconomic family, having a partner that consumes alcohol, having experienced child abuse, not working, not reaching higher education, and being separated from one's partner ${ }^{3,13,25}$. In contrast, being married was a protective factor against IPV ${ }^{13}$.

Furthermore, previous qualitative studies we found on IPV against women in Colombia are on displaced populations only, of whom have their own unique context ${ }^{26,27}$. These studies showed that drivers of household violence were societal gender norms, substance use, attempts to control women's and/or children's behaviours with violence, and daily stressors associated with community problems. Displaced women often become the breadwinner, where they find domestic jobs in cities, and their partners fail to find employment. This enables women to become more economically independent and buy a house. The change in their established gender roles was associated with increased conflict and therefore IPV $^{26,27}$.

The objective of this study, therefore, was to investigate factors that influence IPV against women according to survivors of IPV, professionals from psychological, social and legislative services, and community leaders in the two cities of Cali and Tuluá, Colombia. This paper will help the reader understand the phenomenon of IPV, according to various actors which will aid policy makers to work out how to resolve this alarming problem.

\section{Methods}

\section{Study sites}

This study was conducted in Cali and Tuluá, in the department (i.e. province) of Valle del Cauca with a population of 4.6 million. It is located on the Pacific coast of Southwest Colombia, a region with high levels of poverty, violence, unemployment and poor access to education and health. Cali is the capital and the largest city in the province with over 2.2 million inhabitants and Tuluá is smaller with over 200,000 inhabitants. Most inhabitants of Cali and Tuluá feel that they do not belong to any ethnic group (73\% and $90 \%$ respectively), which may be explained by the diverse and mixed backgrounds of the inhabitants with African, Indigenous and Hispanic ancestors. The most self-recognised ethnicity was Afro-Colombian in Cali and Tuluá: 26\% and 9\% respectively ${ }^{28}$. Many Colombians who were displaced by the armed conflict arrived in Cali and Tuluá ${ }^{19}$.

This qualitative study was performed from June to August 2017 and is part of a larger study on mental health and IPV approved by the ethics committee (CIREH) at the Universidad del Valle (Cali). The larger study includes further qualitative studies on male beliefs and attitudes on IPV and a randomised controlled trial on a psychological cognitive behavioural intervention to improve IPV female survivor's mental health.

This current study consisted of focus group discussions (FGDs) and key informant (KI) interviews. The FGDs were designed to collect data through group interviews with semi-structured guides oriented to scrutinising experiences, perceptions and meanings of IPV among female victims, taking into account the violence ecological framework $^{8}$. Four FGDs were conducted with adult female survivors of IPV; two in Cali (Comuna 20) and two in Tuluá. FGDs were conducted in community leaders' homes, a university (UCEVA, Tuluá) and in a local heath care centre (Red de Salud de Ladera E.S.E. IPS Siloé, Cali). The two FGDs in Cali consisted of six and nine women respectively and six and seven women respectively in Tuluá.

Purposive sampling was used to recruit participants through community leaders and social workers. Those who agreed to participate were also encouraged to bring along acquaintances who had experienced IPV. Three FGDs were performed by two female social workers working in the Comuna 20 who manage many cases of IPV and had experience conducting them. Due to logistical reasons, the last FGD in Tuluá was performed by a male psychiatrist experienced in IPV, who was assisted by a male medical student.

Physical spaces were created where participants could express their feelings and interact with others comfortably. The FGDs began with ice-breaking exercises and those conducted by the social workers were closed with a song "Bebé"29, which shared a message of hope and change.

Fifteen KI interviews were conducted with professionals from the main psychological, social and legal IPV services in Cali and Tuluá, as described in Chart 1. This ensured a wide range of views were obtained from different contexts, not only the female victims' points of view. KI interviews were held in their workplaces, in private offices, or at UCEVA. All participants signed in- 
Chart 1. Key informant interviews conducted.

\begin{tabular}{|c|c|c|}
\hline Key Informant & Cali & Tuluá \\
\hline Forensic Medicine Doctor & $\checkmark$ & $\checkmark$ \\
\hline Family Police Unit (Police officer) & Not available & $\checkmark$ \\
\hline Public prosecutor & $\checkmark$ & $\checkmark$ \\
\hline $\begin{array}{l}\text { Health Center - (Directors of Psychosocial } \\
\text { Units, psychologists) }\end{array}$ & $\checkmark($ Red de Salud de Ladera ESE $)$ & $\checkmark$ (Hospital Rubén Cruz Veléz) \\
\hline Social worker & $\checkmark$ & $\checkmark$ \\
\hline Community leader & $\checkmark($ from MADRE FAMI) & $\checkmark($ from Red de Mujeres) \\
\hline Police officer (Local police station) & $\checkmark$ & $\checkmark$ \\
\hline Casa Matria* $^{*}$ & $\checkmark$ & - \\
\hline House of Justice ${ }^{\star *}$ & $\checkmark$ & Not available \\
\hline \multicolumn{3}{|c|}{$\begin{array}{l}\text { * "Casa Matria" is a municipal government service in Cali that works in the prevention of gender-based violence (GBV) and } \\
\text { provides socio-medico-legal services for survivors of GBV. They also perform monitoring of public policies implemented for } \\
\text { women and gender mainstreaming within the Colombian administration and the Municipal Committee; }{ }^{* *} \text { "House of Justice" is } \\
\text { a municipal level inter-institutional centre of orientation, reference and services to direct its population to medical, social and legal } \\
\text { services. }\end{array}$} \\
\hline
\end{tabular}

formed consent forms and the study was carried out in accordance with the Declaration of Helsinki and the Colombian legislation on ethics for health research. Participant data was managed on principles of confidentiality. Women from FGDs were reimbursed for transport and given refreshments.

Interviews were audio-recorded, literally transcribed, and analysed in Spanish. The analysis was performed manually using the epistemological standpoint of social constructivism ${ }^{30}$. FGDs were conducted using pre-designed questions developed by the study team of psychiatrists, psychologists, health researchers, and social workers. Two of the study's social workers coded the participants' comments using a content analysis. The coding process was followed by a thematic analysis where themes and sub-themes emerged in an iterative process. Study notes added context to the comments. Each social worker, along with authors 1 and 4 discussed the emerging themes in depth. These were validated with other study authors. Sociodemographic questionnaires were also completed by the participants.

\section{Results}

The results from the sociodemographic questionnaires are shown in Table 1. The women from the study were of various ethnicities and predominantly aged 20-34. Most were married or co-habiting and had little education. Many worked full time, but most did not have work contracts, showing the unstable nature of their work. All women in the study had children. The FGDs also found that the majority lived with their abusive partner. All forms of IPV were mentioned by women in this study. Approximately $50 \%$ of women were born in Cali or Tuluá.

Four main themes were found in the analysis and the first theme was divided into six further sub-themes. To ensure the anonymity of the key informants, their identity has been coded (KI= Key informant + number). FGDCALI refers to an FGD from Cali and FGDT refers to an FGD from Tuluá. For more detailed descriptions about participants' comments, see the electronic supplementary material (http://cisalva.univalle.edu.co/ index.php/2019-2021).

\section{Cultural beliefs}

The analysis of the FGDs found that local cultural beliefs are related to IPV. These beliefs were grouped into six important sub-themes, to show how they affect many aspects of society and therefore individuals. The study context has a strong patriarchal culture which we have categorised to be a sub-theme.

\section{Patriarchy}

Many women described how men are believed to be the stronger, smarter sex that therefore controls them. Woman first experienced this from a young age with their fathers and later on 
Table 1. Sociodemographic characteristics of IPV survivor women.

\begin{tabular}{|c|c|c|c|c|c|c|}
\hline \multirow{2}{*}{ City } & \multicolumn{2}{|c|}{ Cali } & \multicolumn{2}{|c|}{ Tuluá } & \multicolumn{2}{|c|}{ Total } \\
\hline & No. & $\%$ & No. & $\%$ & No. & $\%$ \\
\hline \multicolumn{7}{|l|}{ Ethnicity } \\
\hline Hispanic & 0 & 0 & 3 & 23 & 3 & 11 \\
\hline Afro-Colombian & 5 & 33 & 1 & 8 & 6 & 21 \\
\hline Mestizo-Indigenous and Hispanic & 8 & 53 & 8 & 62 & 16 & 57 \\
\hline Mulato-African and Hispanic & 1 & 7 & 0 & 0 & 1 & 4 \\
\hline Other & 1 & 7 & 1 & 8 & 2 & 7 \\
\hline \multicolumn{7}{|l|}{ Age } \\
\hline $18-20$ & 1 & 7 & 0 & 0 & 1 & 3 \\
\hline $20-34$ & 9 & 60 & 8 & 62 & 17 & 61 \\
\hline $35-49$ & 2 & 13 & 3 & 23 & 5 & 18 \\
\hline$\geq 50$ & 3 & 20 & 2 & 15 & 5 & 18 \\
\hline \multicolumn{7}{|l|}{ Marital Status } \\
\hline Married/civil partnership & 10 & 67 & 4 & 31 & 14 & 50 \\
\hline Separated & 1 & 7 & 4 & 31 & 5 & 17 \\
\hline Single & 3 & 20 & 4 & 31 & 7 & 25 \\
\hline Widowed & 1 & 7 & 0 & 0 & 1 & 4 \\
\hline Non-cohabiting partner & 0 & 0 & 1 & 8 & 1 & 4 \\
\hline \multicolumn{7}{|l|}{ Years of Schooling } \\
\hline $0-5$ & 7 & 47 & 6 & 46 & 13 & 46 \\
\hline $6-11$ & 8 & 53 & 5 & 38 & 13 & 46 \\
\hline 13 & 0 & 0 & 1 & 8 & 1 & 4 \\
\hline No data & 0 & 0 & 1 & 8 & 1 & 4 \\
\hline \multicolumn{7}{|l|}{ Occupation } \\
\hline Housewife & 6 & 40 & 5 & 38 & 11 & 39 \\
\hline Various jobs & 1 & 7 & 5 & 38 & 6 & 21 \\
\hline Pensioned & 1 & 7 & 0 & 0 & 1 & 4 \\
\hline Street seller & 3 & 20 & 0 & 0 & 3 & 11 \\
\hline Service provision & 0 & 0 & 2 & 15 & 2 & 7 \\
\hline Other & 3 & 20 & 0 & 0 & 3 & 11 \\
\hline No data & 1 & 7 & 1 & 8 & 2 & 7 \\
\hline \multicolumn{7}{|l|}{ Hours Worked } \\
\hline Full-time & 7 & 47 & 10 & 77 & 17 & 60 \\
\hline Part-time & 3 & 20 & 2 & 15 & 5 & 18 \\
\hline Sporadic & 2 & 13 & 1 & 8 & 3 & 11 \\
\hline No data & 3 & 20 & 0 & 0 & 3 & 11 \\
\hline \multicolumn{7}{|l|}{ Type of Contract } \\
\hline Independent & 4 & 27 & 3 & 23 & 7 & 25 \\
\hline Contract worker & 1 & 7 & 1 & 8 & 2 & 7 \\
\hline No contract & 8 & 53 & 8 & 62 & 16 & 57 \\
\hline Undefined & 0 & 0 & 1 & 8 & 1 & 4 \\
\hline No data & 2 & 13 & 0 & 0 & 2 & 7 \\
\hline Woman with children & 15 & 100 & 13 & 100 & 28 & 100 \\
\hline
\end{tabular}

Source: Elaborated by the authors.

with romantic partners: "Is it not like the control that they have always taught us? I remember that men, dads, are always right. Who made all the decisions at home? So, you have to lower your head to your husband..." (FGDT).

\section{Gender roles}

Participants frequently mentioned how they were expected to perform household chores and not study or work: "this is what we are for and this is what we were born for" (FGDCALI), "we 
are good for this; we don't need to study for this" (FGDCALI). Housework was described as not being recognised as a "job" in their culture, and the chores carried out by women were undervalued.

This undervaluation of a women's role was used as a method of showing male superiority. Women in the study also failed to recognise their worth, showing how many women hold patriarchal values also. However, this belief seems to be changing as one woman told the other participants that they must "recognise that we are valuable...", (FGDCALI) with which the majority of women agreed.

\section{Normalisation of violence}

As IPV has been legitimatised at individual and societal levels, boys and girls are brought up witnessing it from an early age which has led to the normalisation of violence. Women described how violence was taught to them by their parents in their upbringing and early socialisation: "[...] you get accustomed that it is men who shout, that it is men who hit" (FGDT).

They also discussed how this behaviour is normalised on a society level where there is a "macho" culture that legitimises violence: "I don't think it is that we are weak, but that society made us see ourselves that way and we have accepted it. So, men have used their machismo to ensure that we go along with it (IPV), so that everyone sees that they are macho and they want to fix everything with violence" (FGDT).

\section{Unawareness of rights}

This was recognised as an important factor, more so by the KIs than the participants. A KI from Cali described women as having "[...] a total unawareness of their rights ..." (KI5) which was echoed by other KIs. Only one participant recognised this:

"Putting up with things $[\ldots]$ one does not recognise or know what abuse is, I believe that this is what is behind all types of violence [...] if one had known before... or assisted these meetings..." (FGDCALI). Two KIs also believed how more work needs to be done with women to raise "awareness of their rights" (KI6) and another mentionedhow they are already working on this.

\section{Economic dependence}

The fact that women are not economically independent was perceived as an important factor for women having to comply with the violence. Women described how men controlled the mon- ey in the home, whether they made it themselves or not: " $[\ldots]$ he catches me and counts my earnings, my money and he wants to use my money, well, for what he wants to spend it on..." (FGDCALI).

By controlling the money, they were able to continue to exert their control over women and use it to blackmail them. For instance, many women in the study mentioned how they were not receiving child maintenance from their ex-partners who used this as a tool to try to persuade them to return: "[...] when you get separated, they start to take the money away and they start to tell you... 'you will starve without me, you will starve if I don't give you anything, if you don't come back to me, I'm not going to give you anything"' (FGDCALI).

\section{Men own women}

As men in this culture legitimately control women, they treat women as their property. A piece of property does not have the right to choose when it wants to have sexual relations and can be used by its owner whenever the owner wishes to use it. This therefore meant that women lacked autonomy in their relationships: "you have to wait for the husband to feel like being with their wife, because I don't have that right" (FGDT). What-is-more, once a man had become the owner of his property, he had a life-time purchase, and the control did not end when the relationship did: "[...] I separated 11 years ago from the father of my son, but whether I have a partner or not he is always there... he has hit me because according to him he is still my lover..." (FGDT).

\section{Jealousy}

Women gave many examples of how their partners were jealous of them which made them angry and violent. This was another method of exerting control over the women. Women from the group were accused of having affairs and working as prostitutes: "[...] if you speak with so-and-so it's because she is passing you messages and she is giving them to you from so-and-so $[\ldots]$ he wants to know who is passing you messages..." (FGDT). The word "whore" ("puta" in Spanish) is a demeaning word, which is used to describe women, not men. They are threatening them that if they do not abide by the established societal gender norms, specifically sexual norms, then they will be labelled as a "whore".

Women described learning about these sexual norms as children, while growing up in their 
household: "[...] my father was always drinking. He took my mum out to drink and when my mum was sleeping, he slept with another woman next to her..." (FGDCALI).

\section{Alcohol abuse}

Alcohol and substance abuse is a big problem in the study population and the women associated their partner's drinking with jealously: “[...] he was drunk and so he hit me because he was suspicious, just in case...it was because he was drunk and I had come home from work really tired [...] it was always when he came home drunk" (FGDT). Women explained that the primary reason for their partner hitting them was because he was drunk. The second reason was that he was jealous. This shows how alcohol is used as an excuse for committing IPV, where men loses control due to alcohol and therefore claim to not be responsible for their actions.

\section{Personal history of IPV}

Women from the FGDs associated child abuse experienced by their partners as a cause for the violence inflicted by them: "[...] the father of my children had a childhood! His mother abandoned him, his aunty brought him up, he was abused [...] child abuse is not normal to me, but he told me 'you have to be hard on them, that's how I was brought up" (FGDCALI). This quote also shows how beliefs are intergenerationally transferred. Adults behave the way their parents behaved as it is assumed to be the correct way.

\section{Discussion}

This study explored the influencing factors of IPV according to female survivors of IPV, professionals from psychological, social and legal services and community leaders in Cali and Tuluá, Colombia. This enabled us to focus on all four levels of the violence ecological framework ${ }^{8}$ and triangulate data from a diverse group of actors with existing literature. A rich analysis of IPV in the Colombian context is presented here.

Factors found to be associated with IPV were divided into the following four themes: cultural beliefs, jealousy, alcohol abuse, and personal history of IPV. The first theme was the most important that was divided into six sub-themes: patriarchy, gender roles, normalisation of violence, unawareness of rights, economic dependence, and "men own women". These, however, were all inter-related and are underpinned by patriarchal values.

High levels of violence were described by the study participants, which was not surprising given the violent history of Colombia. As the most recent armed Colombian conflict lasted decades, it has inevitably affected, directly or indirectly, most of the population alive today or in previous generations. Colombia saw an enormous displacement of citizens from the countryside to cities after they experienced, witnessed or were threatened with many violent atrocities. This has caused many deep-rooted and complex social, economic, political and cultural problems. The displaced population's occupational skills, generally in agriculture, have limited value in the cities that they fled to and they struggle to find work. Studies on male homicides have found that men, due to lack of formal education and job opportunities, struggle to remain the breadwinner and often lose their sense of control, dignity and respect, which are important parts of their masculinity ${ }^{31}$. Moreover, it is often women that find work more easily in domestic jobs for instance, and they become the new breadwinner. As men find themselves cut out of mainstream society, an appealing means of regaining a dignified living and their sense of masculinity, is to work in organised crime, such as drug trafficking, which is a significant problem in both our study sites. This perpetuates different types of violence in their communities; gang and interpersonal violence, which have subsequent effects on IPV ${ }^{31}$.

The patriarchal values of domination found in this study, created a culture that imposed a series of regulatory programs on the duties of women and men, where inequalities between the two were established ${ }^{32,33}$. From the accounts in the study, it was observed how IPV mostly occurred in private spaces of socialisation, which makes it harder to intervene ${ }^{8}$. Participants from this study gave examples of how men exerted their power over women and controlled them, which other studies have also described ${ }^{11,32,33}$.

The survivors of IPV held similar views to the KIs. However, the survivors linked individual and relationship factors more often than the KIs, who more frequently spoke of societal or cultural norms. Their different perspectives on the same problem highlighted different levels to be tackled to address this issue.

Study participants gave imaginaries of gender as they described the social context where they lived, socialised and interacted. They shared so- 
cial representations and perspectives on gender differences which situated females in an inferior position where they can only exist as wifemother-house-wife-abused woman. As they have not interpreted, lived or acquired their cultural norms equitably, gender inequalities were generated and practices that favour the male gender were preserved. Other studies also found gender norms to be associated with IPV in Colombia in displaced population ${ }^{26,27}$. A recent systematic review and meta-analysis in low and low-middle income countries found that interventions to address gender norms have promising potential to reduce IPV against women ${ }^{34}$, although there are some limitations in comparing these results with a middle-income country. These findings are important for the creation of interventions which should be culturally sensitive, tackle gender norms and promote gender equality $y^{35}$.

Study participants explained how males and females assume characteristics as if they were innate. Other authors have described how societies impose tasks and responsibilities to each gender due to their biological conditions $s^{32}$. These gender roles are an example of human social order that exists as a product of human activity where repeated activities become habits or customs, including IPV $32,36,37$. Practices that dominate women were also preserved in this study where woman were "born" to be a housewife, and "don't need to study" for that role.

The concept of gender is transferred intergenerationally where it becomes normalised ${ }^{3,25}$. Participants described that people behaved the way they did as they knew no other way. They did not question the beliefs and practises which were culturally used in their upbringing. Ribero and Sánchez ${ }^{13}$ found that when male partners had experienced child abuse, there was an increased probability that they would abuse their wife. Women and KIs from this study described these findings also. Gil and Loret $^{38}$ explain how boys who have experienced domestic violence grow up to identify with the "aggressor" and reproduce this violence with their partners. Women often identify more closely with the "victim" and accept this role. These distinct identities and roles reinforce hegemonic patterns that perpetuate violence. The violent culture is sustained by the social approval it has been given to the extent that is has become a valid act and an unspoken social guideline that is legitimised $33,6,26,27,32,33$.

IPV has therefore become a structural problem also which was explained by a KI . There was powerlessness in his words as he described how he believed that IPV is a problem that cannot be solved on an individual level. Blame was placed on society rather than individuals where boys learn to be abusive from their fathers and that IPV is a "[...] structural problem...it's cultural, it's historical, and they educated us this way and made us like this". There was an edge of defensiveness to his words and an acceptance of issues. Such attitudes, give authorities an excuse to allow the violence to continue and that they have no role in policing it. Previous studies also explained how, in Colombia, there is a social and institutional tolerance to $\mathrm{GBV}^{3,4,13,25,33}$.

The normalisation of violence in the study context means that some women do not acknowledge their violent circumstances. Only a few participants linked knowledge of their rights to be associated with IPV. One woman described how she had tolerated mistreatment as she did not know what abuse was. She insinuated that if she had known what it was, she may not have accepted it. The KIs thought that this was an area that warranted more work. Participants were questioned separately about legal services for IPV and they mentioned many problems accessing it but did not associate these with IPV. These findings will be published separately. Another area of research that would assist interventions for the prevention of IPV is how women cope with IPV. This was not part of the scope of this study. However, we noticed that as the participants shared how they lived in such violent communities where gang violence, interpersonal violence and IPV is so common and normalised, they do not take action on it but accept it and try to continue their lives in a way that is "normal" for them. Part of future interventions should therefore include education on IPV.

The study participants mentioned many economic stresses in their households which meant they were often economically dependent on their partners and financial strains were a cause for conflict. The economic status of the family has been found to be important in other studies, where those from lower socioeconomic classes experience more IPV than higher classes ${ }^{25}$. In cases where women did not work, but depended on their partner for their rent, food, and children's school fees, etc., they had no option to leave their homes for fear of losing these 'benefits'. In Colombia, it is difficult for single women with children to access social, housing and educational benefits. Furthermore, Women's Refuges are scarce or cannot respond to the demand.

Differential access to education is also related to economic dependence and was mentioned by 
the study's participants, who had obtained low levels of education. They described how education was deemed unnecessary for housewives and in some cases was prohibited. Gómez López et al. ${ }^{3}$ found that women who had reached higher education experienced less IPV (69\%) compared to those who had nil or primary school education (77\%) and secondary school education $(77 \%)^{3}$. Interestedly, they found that women who were unemployed experienced less IPV (67\%) than those who worked (76\%), showing that employment is not necessarily protective ${ }^{3}$. When women break cultural norms by working and/or become the breadwinner, this may cause conflict $^{26,27}$. Women were not only prohibited from obtaining an education, but also often from working. Or, if they were able to work, instead of taking their normal role as housewives, the women in this study mentioned this was an associated risk factor for IPV, where their partners were jealous of them when they left the home and believed they would be unfaithful. Also, the women explained how their partners tried to maintain economic control in the household by taking their money from them when they received their pay, thus creating another source of conflict at home.

We created the sub-theme "men own women" as the participants shared many examples of how they were "property" that belonged to their partners. They had restrictions on what they could do with their bodies and men had control of when and how they wanted to use them. For instance, one woman described how she had to wait for her husband to want to have intercourse and that she did not have the "right" to initiate it. Intercourse is seen as something obligatory that women must provide when their partner desired it. Participants also faced restrictions on their movements where a woman and KIs explained how women are "kept locked-up". Women gave examples of how their ex-partners still considered them their property after they had left them and therefore continued to abuse them. Colombian studies found that women are at an increased risk of IPV after they have separated from their partner $^{3,13,26,27}$. This may be due to the loss of control a man feels about his partner leaving him. To him, the only way to resolve this conflict is further violence. Also, women in this context may be less able to protect themselves due to limited access to organisations to help them, limited resources for survivors of IPV such as shelters, or financial support. This sub-theme is closely linked to jealously, as the women "belong" to their partners.

Participants' partners were described as over-suspicious to keep them under surveillance, as did other family members. Jealousy was mentioned to be exacerbated by alcohol, which was also associated with increased violence. Interestingly, alcohol was mentioned to be associated with IPV by only a few women in our study and by only two KIs. However, other Colombian studies have found that if partners consume alcohol there was a $13 \%$ increase in probability of IPV in their home ${ }^{13}$, or a $6 \%$ increased probability if they consumed it to get drunk regularly $y^{25}$. Perhaps these differences are due to the interview methods where publicly, women may not want to mention drug or alcohol abuse. Devries et al. ${ }^{39}$ mentioned how stigma around alcohol exists to different degrees depending on the location which can result in under-reporting of its use.

\section{Study limitations}

The women who agreed to attend the FGDs may have been different from the women who declined to attend. For instance, women who were exposed to more severe and/or frequent IPV or those with more severe mental or physical health problems may not have attended. Limitations of the FGD may include social desirability bias, which may have prevented some women from sharing views which they thought to be unique to them for which they would have been stigmatised. However, as some participants shared their experiences, it appeared to encourage others to do so. The FGDs appeared therapeutic for the participants as they had a safe space in which to share their problems, which they may not normally have. Also, the women's accounts may have been subject to recall bias, so information may have been missed. One FGD in Tuluá had to be conducted by a male psychiatrist who may have influenced the dynamic of the group and therefore the women's responses. However, a community leader also attended this group, who was enthusiastic about her community sharing their experiences of IPV. We did not notice any differences in the content of this FGD compared to the others. Unfortunately, it was not possible to carry out more sessions with the women participating in the FGDs, which would have increased the amount of information obtained. 


\section{Conclusion}

This study contextualised the situation of IPV where it was described as a sociocultural construction formed by patriarchal values ingrained in community and societal norms and individual processes. It is caused by a complex interplay of different factors at the levels of individuals, re- lationships, community and social following the ecological model of violence. This study found cultural factors to be the most important associated factor with IPV, particularly given its long, violent history. Context specific interventions are needed to address these findings, with particular attention to societal and community beliefs which perpetuate patriarchal values and gender norms.

\section{Collaborations}

SE Lennon: Data curation (Equal), Formal analysis (Equal), Investigation (Equal), Project administration (Equal), Supervision (Equal), Writing-original draft (Equal), and Writing-review \& editing (Equal). AM Ramírez Aramburo: Data curation (Equal), Formal analysis (Equal), Investigation (Equal), Writing-original draft (Equal), and Writing-review \& editing (Equal). EM Morales Garzón: Data curation (Equal), Formal analysis (Equal), Investigation (Equal), Writing-original draft (Equal), and Writing-review \& editing (Equal). MA Arboleda: Conceptualization (Equal), Data curation (Equal), Formal analysis (Equal), Funding acquisition (Equal), Investigation (Equal), Methodology (Equal), Writing-original draft (Equal), and Writing-review \& editing (Equal). SG Pacichana-Quinayaz: Conceptualization (Equal), Formal analysis (Equal), Funding acquisition (Equal), Investigation (Equal), Methodology (Equal), Project administration (Equal), Supervision (Equal), and Writing-review \& editing (Equal). A Fandiño-Losada: Conceptualization (Equal), Data curation (Equal), Formal analysis (Equal), Funding acquisition (Equal), Investigation (Equal), Methodology (Equal), Project administration (Equal), Resources (Equal), Supervision (Equal), and Writing-review \& editing (Equal). GI Rodas Muñoz: Conceptualization (Equal), Funding acquisition (Equal), Investigation (Equal), Resources (Equal), and Writing-review \& editing (Equal). MI Gutiérrez-Martínez: Conceptualization (Equal), Funding acquisition (Equal), Project administration (Equal), Resources (Equal), Supervision (Equal), and Writing-review \& editing (Equal). 


\section{Acknowledgments}

This study was performed as part of the research project "Evaluación de una Intervención Cognitivo Conductual para Víctimas de la Violencia Intrafamiliar en Cali y Tuluá, Valle del Cauca, Colombia", funded by the Colombian National Department of Science, Innovation and Technology. COLCIENCIAS, Grant Nr. RC-756-2016.

The authors would like to thank Francisco Bonilla-Escobar, Gisel Osorio and Edgar J. Muñoz for contributing to the conceptualization of the project idea; and to thank Luis Alberto Valencia, Iván Escobar, Whitney Córdoba, Jennifer Nessim and Nathalia Ledesma for their support during the field work of this study. Finally, we would like to thank the women victims of intimate partner violence who participated in this study.

\section{References}

1. World Health Organization (WHO). Global and regional estimates of violence against women: prevalence and health effects of intimate partner violence and non -partner sexual violence. Geneva: WHO; 2013.

2. Breiding M, Basile KC, Smith SG, Black MC, Mahendra RR. Intimate partner violence surveillance: Uniform definitions and recommended data elements. Atlanta: CDC; 2015.

3. Gómez López C, Murad R, Calderón MC. Historias de violencia, roles, prácticas y discursos legitimadores. Violencia contra las mujeres en Colombia 2000-2010. Bogotá: PROFAMILIA; 2013.

4. Instituto Nacional de Medicina Legal y Ciencias Forenses (INMLCF). Forensis 2018: Datos para la Vida. Bogotá: INMLCF; 2019.

5. Dicola D, Spaar E. Intimate Partner Violence. Am Fam Physician 2016; 94(8):646-651.

6. Sanchez-Prada A, Delgado-Alvarez C, Bosch-Fiol E, Ferrer-Perez VA. Implicit and Explicit Attitudes Toward Intimate Partner Violence Against Women: An Exploratory Study. J Interpers Violence 2021; 36(910):4256-4276.

7. Estrada AM, Ibarra C, Sarmiento E. Regulación y control de la subjetividad y la vida privada en el contexto del conflicto armado colombiano. Rev Estud Soc 2003; 15:133-149.

8. Heise LL. Violence against women: An integrated, ecological framework. Violence Against Women 1998; 4(3):262-290.

9. Organización Panamericana de la Salud (OPS). Prevención de la violencia sexual y violencia infligida por la pareja contra las mujeres: qué hacer y cómo obtener evidencias. Washington, DC: OPS; 2011.

10. Fulu E, Warner X, Miedema S, Jewkes R, Roselli T, Lang J. Why do some men use violence against women and how can we prevent it? Quantitative findings from the United Nations Multi-country Study on Men and Violence in Asia and the Pacific. Bangkok: UNDP, UNFPA, UN Women, UNV; 2013.

11. Fleming PJ, McCleary-Sills J, Morton M, Levtov R, Heilman B, Barker G. Risk factors for men's lifetime perpetration of physical violence against intimate partners: results from the International Men and Gender Equality Survey (IMAGES) in eight countries. PLoS One 2015; 10:e0118639.

12. Yakubovich AR, Stöckl H, Murray J, Melendez-Torres GJ, Steinert JI, Glavin CEY, Humphreys, JK. Risk and Protective Factors for Intimate Partner Violence Against Women: Systematic Review and Meta-analyses of Prospective-Longitudinal Studies. Am J Public Health 2018; 108(7):e1-e11.

13. Ribero R, Sánchez F. Determinantes, efectos y costos de la violencia intrafamiliar en Colombia. Bogotá: CEDE - Universidad de Los Andes; 2004.

14. McCarthy KJ, Mehta R, Haberland, NA. Gender, power, and violence: A systematic review of measures and their association with male perpetration of IPV. PLoS One 2018; 13(11):e207091.

15. Heise L, Garcia-Moreno C. Violence by Intimate Partners. In: Krug EG, Dahlberg LL, Mercy JA, Zwi AB, Lozano R, editors. World report on violence and health. Geneva: WHO; 2002. 
16. World Health Organization (WHO). London School of Hygiene and Tropical Medicine (WHO/LSHTM). Preventing intimate partner and sexual violence against women: taking action and generating evidence. Geneva, London: WHO/LSHTM; 2010.

17. Fajardo D. Estudio sobre los orígenes del conflicto social armado, razones de su persistencia y sus efectos más profundos en la sociedad colombiana. Conflicto social y rebelión armada en Colombia. Bogotá: Centro Nacional de Memoria Histórica; 2015.

18. The United Nations Refugee Agency. Colombia [Internet]. [cited 2020 Jan 20]. Available from: https://www. unhcr.org/uk/colombia.html?query=colombia.

19. Historical Memory Group. BASTA YA! Colombia: Memories of War and Dignity. General Report by the Historical Memory Group. English version [Internet]. 2016 [cited 2020 Jan 20]. Available from: http://www. centrodememoriahistorica.gov.co/descargas/informes2016/basta-ya-ingles/BASTA-YA-ingles.pdf.

20. United Nations Office on Drugs and Crime (UNODC). Global Study on Homicide 2019. Vienna: UNODC; 2019.

21. Guerrero R, Fandiño-Losada A. Is Colombia a violent country? Colomb Med 2017; 48(1):9-11.

22. Kiss L, Schraiber LB, Hossain M, Watts C, Zimmerman C. The Link Between Community-Based Violence and Intimate Partner Violence: The Effect of Crime and Male Aggression on Intimate Partner Violence Against Women. Prev Sci 2015; 16(6):881-889.

23. Tamayo FL, Norza E. Midiendo el crimen: cifras de criminalidad y operatividad policial en Colombia, año 2017. Rev Criminalidad 2018; 60(3):49-71.

24. United Nations (UN), Department of Economic and Social Affairs, Population Division. World Population Prospects: The 2017 Revision. New York: UN; 2017.

25. Barrientos J, Molina CA, Salinas D. Las causas de la violencia intrafamiliar en Medellín. Perfil de Coyuntura Económica 2013; 22:99-112.

26. Hynes ME, Sterk CE, Hennink M, Patel S, De Padilla L, Yount KM. Exploring gender norms, agency and intimate partner violence among displaced Colombian women: A qualitative assessment. Glob Public Health 2016; 1(1-2):17-33.

27. Wirtz AL, Pham K, Glass N, Loochkartt S, Kidane T, Cuspoca D, Rubenstein LS, Vu A. Gender-based violence in conflict and displacement: qualitative findings from displaced women in Colombia. Confl Health 2014; 8:10.

28. Departamento Administrativo Nacional de Estadística (DANE). Censo General del 2005. Bogotá: DANE (Colombia); 2010.

29. Rebolledo M. Ella. In: Jean C. Pafuera Telarañas [CD]. Madrid: EMI Records; 2004.

30. Berger PL, Luckmann T, Zuleta S. La construcción social de la realidad. Buenos Aires: Amorrortu; 1968.
31. Gamlin JB, Hawkes SJ. Masculinities on the Continuum of Structural Violence: The Case of Mexico's Homicide Epidemic. Soc Polit 2017; 25(1):50-71.

32. Montes de Oca YPA, Valdez Medina JL, González -Arratia López-Fuentes NI. Satisfacción con los Roles de Género. Rev Electrónica Psicol Iztacala 2012; 15(4):1440-1453.

33. Fondo de las Naciones Unidas y el Gobierno de España para el cumplimiento de los Objetivos de Desarrollo del Milenio (MDGF). Estudio sobre Tolerancia Social e Institucional a la Violencia basada en Género en Colombia. Bogotá: MDGF; 2010.

34. Semahegn A, Torpey K, Manu A, Assefa N, Tesfaye $\mathrm{G}$, Ankomah A. Are interventions focused on gender-norms effective in preventing domestic violence against women in low and lower-middle income countries? A systematic review and meta-analysis. Reprod Health 2019; 16:93.

35. World Health Organization (WHO). Strengthening health systems to respond to women subjected to intimate partner violence or sexual violence: a manual for health managers. Geneva: WHO; 2017.

36. Saldívar Garduño A, Díaz Loving R, Reyes Ruiz NE, Armenta Hurtarte C, López Rosales F, Moreno López M, Romero Palencia A, Hernández Sánchez JE, Domínguez Guedea M. Roles de género y diversidad: Validación de una escala en varios contextos culturales. Acta Investigación Psicol 2015; 5(3):2124-2147.

37. Lamas M. Cuerpo: diferencia sexual y género. México: Taurus; 2002.

38. Gil E, Lloret I. La violencia de género. Barcelona: Editorial UOC; 2007.

39. Devries KM, Child JC, Bacchus LJ, Mak J, Falder G, Graham K, Watts C, Heise L. Intimate partner violence victimization and alcohol consumption in women: A systematic review and meta-analysis. Addiction 2014; 109(3):379-391.

Article submitted 08/02/2020

Approved 08/07/2020

Final version submitted 10/07/2020

Chief editors: Romeu Gomes, Antônio Augusto Moura da Silva 